\title{
Lutein prevents osteoarthritis through Nrf2 activation and downregulation of inflammation
}

\author{
Yan-Qin Qiao ${ }^{1}$, Pan-Feng Jiang ${ }^{1}$, Yan-Zheng Gao ${ }^{2}$
}

${ }^{1}$ First Department of Orthopedics, Xinxiang Central Hospital, Xinxiang, Henan, China 2Department of Orthopedics, Henan Provincial People's Hospital, Henan, China

Submitted: 29 September 2015

Accepted: 11 February 2016

Arch Med Sci 2018; 14, 3: 617-624

DOI: https://doi.org/10.5114/aoms.2016.59871

Copyright $\odot 2016$ Termedia \& Banach

\section{Abstract}

Introduction: Osteoarthritis is an inflammatory disorder associated with oxidative stress and apoptosis leading to cartilage destruction and impairment of cartilage formation. In the present study, we studied the protective effect of lutein against monosodium iodoacetate (MIA)-induced osteoarthritis in primary chondrocyte cells.

Material and methods: Oxidative stress was determined through testing antioxidant status, reactive oxygen species levels and lipid peroxide content. Also, Nrf2 expression and its downstream target genes HO-1 and NQO-1 were determined. Inflammation was analyzed through NF-kB, COX-2 and pro-inflammatory cytokines (IL-6, TNF- $\alpha$, IL-1 $\beta$ ). In addition, the effects of MIA and lutein on mitochondrial membrane potential and caspase- 3 levels were analyzed.

Results: The results showed that lutein treatment significantly increased the cell viability of chondrocytes and offered significant cytoprotection by enhancing the antioxidant defense mechanisms and reducing oxidative stress (reactive oxygen species and lipid peroxidation). Lutein treatment showed anti-inflammatory effects by downregulating inflammatory proteins (NF- $\kappa B$, COX-2) and pro-inflammatory cytokines (IL-6, TNF- $\alpha$, IL-1 $\beta$ ). Lutein reduced MIA-induced apoptosis through maintaining mitochondrial membrane potential and downregulating caspase-3 activity.

Conclusions: The present study shows significant cytoprotection offered by lutein against MIA-induced oxidative stress, inflammation and apoptosis by the modulatory effect of NF-KB and Nrf2 activation.

Key words: oxidative stress, reactive oxygen species, lutein, osteoarthritis, inflammation.

\section{Introduction}

Osteoarthritis (OA) is identified as the most common musculoskeletal disorder with deregulation in the inflammatory pathway and apoptosis. The degenerative joint disease is associated with loss of cartilage function which mainly occurs as an imbalance between anabolic and catabolic pathways of matrix formation, with more pronounced catabolism of cartilage [1]. The associated risk factors of osteoarthritis include age, genetic predisposition, injury, obesity, etc. An important contributor to cartilage function is chondrocytes, cells which are involved in production and formation of matrix proteins. Terminally differentiated chondrocytes undergo apoptosis with ultimate matrix calcification and vascular inva-

\author{
Corresponding author: \\ Yan-Zheng Gao \\ Department of Orthopedics \\ Henan Provincial \\ People's Hospital \\ 7 Weiwu Road \\ Zhengzhou \\ 450000 Henan, China \\ Phone: +8637165964376 \\ E-mail:yanzhenggao@ \\ outlook.com
}


sion of cartilage. Thus, the principle functional loss of chondrocytes is the major event in osteoarthritis. Oxidative stress and activation of inflammation has been known to be an important mediator in the development of osteoarthritis [2, 3]. Thus, an effective protective strategy could be established by targeting oxidative stress and apoptosis, thereby improving the functional status of chondrocytes. Recently, there has been much focus on natural compounds with potent antioxidant properties, by which they target redox signaling and ameliorate negative effects leading to disease status $[4,5]$. In the present study, we aimed to study the potential role of lutein against monosodium iodoacetate (MIA) induced osteoarthritis. Lutein $\left(\mathrm{C}_{40} \mathrm{H}_{56} \mathrm{O}_{2}\right)$ is a tetraterpenoid that has been identified as a potent antioxidant. Rich sources are dark green leafy vegetables, eggs and fruits. The hydroxyl group of lutein scavenges reactive oxygen species and exerts protection against oxidative stress and inflammatory diseases [6-8]. Lutein suppresses arthrosclerosis by reducing oxidative stress and inflammation [9]. Anti-inflammatory effects of lutein in lipopolysaccharide (LPS)-induced inflammation in macrophages and skin inflammation were mediated through downregulating inflammatory proteins and cytokine expression $[9,10]$. Furthermore, the protective role of lutein against ischemic injury in the small intestine and kidney $[11,12]$ has been reported. Lutein's protection against paracetamol, carbon tetrachloride and ethanol induced liver damage is mediated through its antioxidant effects [13]. In this study, we aimed to analyze the action of lutein against osteoarthritis by evaluating oxidative stress and inflammatory mechanisms.

\section{Material and methods}

\section{Chemicals}

Lutein, minimum essential Eagle's medium, fetal bovine serum (FBS), trypsin, penicillin, streptomycin, DCF-DA (dichloro-dihydro-fluorescein diacetate), and $\mathrm{DiOC}_{6}$ (3,3'- dihexyloxacarbocyanine iodide) were purchased from Sigma Aldrich Chemicals Private Limited, USA. Primary monoclonal antibodies (NF-KB, Nrf2, HO-1, COX-2, NQO1) and secondary antibodies were purchased from Cell Signaling Technology, USA. ELISA kits (IL-6, IL-1 $\beta$, TNF- $\alpha$ and caspase-3) were procured from Abcam, USA.

\section{Cell culture and treatment schedule}

Primary rat chondrocytes were used for the present study. The isolation and cell culture were carried out as described previously [14]. All the protocols were approved by the animal ethics committee at the Department of Orthopedics, Xinxiang Central Hospital, Xinxiang, China. Five- week-old Sprague-Dawley rats were used for the present study. The articular cartilage from the femoral heads of rats were excised and digested in trypsin-EDTA for 20 min followed by collagenase II treatment for $3 \mathrm{~h}$. The primary chondrocytes were cultured in minimum essential Eagle's medium supplemented with $10 \%$ FBS and antibiotics. The chondrocytes at 3-5 passages were used for all the experiments. The cytotoxic concentration of MIA was determined and the protective dose of lutein was identified by pre-treating the cells with different concentrations of lutein followed by MIA. The shortlisted concentrations of MIA and lutein were used for further studies.

Briefly, articular cartilages of femoral heads were harvested from the 4-week-old male Sprague-Dawley rats. The cartilage pieces were digested with trypsin-EDTA and $0.2 \%$ Collagenase II (Sigma, St. Louis, MO) for $15 \mathrm{~min}$ and $3 \mathrm{~h}$, respectively. The chondrocytes were cultured in Mini-mum essential Eagle's medium (MEM, Gibco, New York, NY) at $378^{\circ} \mathrm{C}$ in $5 \% \mathrm{CO}_{2}$. For all experiments, the cells of early passages (primary to 3 ) were used.

\section{Cell viability}

Cell viability was assessed by MTT (3-(4,5-dimethylthiazol-2-yl)-2,5-diphenyltetrazolium bromide) assay. Briefly, cells $\left(1 \times 10^{5}\right)$ were seeded and treated with different concentrations of MIA $(2,4,6,810 \mu \mathrm{M})$ for 24 and $48 \mathrm{~h}$. The IC 50 value was determined. Further, cytoprotective concentration was determined by treating with lutein $(0.5,1,5$ and $10 \mu \mathrm{M})$ for $24 \mathrm{~h}$ followed by MIA treatment. After the complete treatment schedule, cells were incubated with MTT $(5 \mathrm{mg} / \mathrm{ml})$ and resulting formazan crystals were dissolved in DMSO (dimethyl sulfoxide) and the absorbance was read at $570 \mathrm{~nm}$. Cell viability was calculated by comparing the values to that of control cells [15].

\section{Intracellular reactive oxygen species (ROS) generation}

For ROS determination, the cells $\left(1 \times 10^{5}\right)$ were treated with lutein for $24 \mathrm{~h}$, followed by DCF-DA for $30 \mathrm{~min}$. After that the cells were washed in PBS and treated with MIA for $48 \mathrm{~h}$. The cells were trypsinized and suspended in PBS and ROS levels were measured fluorimetrically (excitation wavelength $480 \mathrm{~nm}$, emission wavelength $520 \mathrm{~nm}$ ). The results were expressed as \% DCF fluorescence per $\mathrm{mg}$ of protein samples compared to the control group [16].

\section{Lipid peroxidation}

After treatment, cells were incubated in $8 \%$ sodium dodecyl sulfate (SDS); $0.8 \%$ thiobarbituric 
acid (TBA) in 20\% acetic acid and heated for $1 \mathrm{~h}$ at $90^{\circ} \mathrm{C}$. A butanol/pyridine mixture was added and it was shaken vigorously, then centrifuged at 4000 rpm for $10 \mathrm{~min}$, and the organic layer was read at $532 \mathrm{~nm}$. The lipid peroxide content was expressed as $n$ moles of TBA reactants/mg of protein [17].

\section{Antioxidant enzyme activities}

Superoxide dismutase (SOD) activity: The SOD activity was determined as described by Sun et al. [18]. The assay is based on reduction of nitro blue tetrazolium (NBT). $1 \mathrm{U}$ of SOD activity = amount required for $50 \%$ inhibition of nitro blue tetrazolium chloride (NBT) reduction. The SOD activity is expressed as $\mathrm{U} / \mathrm{mg}$ of protein. Catalase (CAT) activity: The activity was determined according to the method described by Aebi (1974) [19]. The reaction mixture contained tissue homogenate and $30 \mathrm{mM} \mathrm{H}_{2} \mathrm{O}_{2}$ in a $50 \mathrm{mM}$ phosphate buffer $(\mathrm{pH}$ 7.0). The activity was estimated by the decrease in absorbance of $\mathrm{H}_{2} \mathrm{O}_{2}$ at $240 \mathrm{~nm}$. Glutathione-S-transferase (GST) activity: The reaction between 1-chloro-2,4-dinitrobenzene (CDNB) and reduced glutathione results in formation of dinitrophenylthioether, which is measured at $340 \mathrm{~nm}$ [20]. $1 \mathrm{U}$ = amount of enzyme producing $1 \mathrm{mmol}$ of CDNB-GSH conjugate/min. Glutathione peroxidase (GPx) activity: The GPx activity was determined as described by Paglia and Valentine (1967) [21]. The oxidized glutathione (GSSG) is reduced by glutathione reductase and NADPH (nicotinamide adenine dinucleotide phosphate). The oxidation of NADPH to $\mathrm{NADP}^{+}$is measured by the decrease in absorbance at $340 \mathrm{~nm}$. GPx activity is expressed as $\mathrm{U} / \mathrm{mg}$ of protein.

\section{Mitochondrial membrane potential $(\Delta \psi \mathrm{m})$}

The cells $\left(1 \times 10^{5}\right)$ were treated with lutein for $24 \mathrm{~h}$ followed by MIA. After treatment, the cells were washed with PBS and treated with DiOC (3) and incubated for $1 \mathrm{~h}$. The fluorescence intensity was measured (excitation wavelength of $488 \mathrm{~nm}$ and emission wavelength at $500 \mathrm{~nm}$ ). The mitochondrial membrane potential was calculated per mg of protein, while the control was set to $100 \%$.

\section{ELISA: IL-6, TNF- $\alpha$, IL-1 $\beta$ and caspase-3 levels}

After the treatment schedule mentioned above, the supernatant was analyzed for interleukins levels of TNF- $\alpha$, IL- $1 \beta$ and IL- 6 levels using ELISA kits (Sigma). The levels of interleukins were expressed as $\mathrm{pg} / \mathrm{ml}$. The cellular protein was analyzed for caspase-3 activity. Results were expressed as RU/ $\mathrm{mg}$ of protein. The absorbance was measured using an ELISA reader (MTP-800 Microplate reader; Corona Electric, Tokyo, Japan).

\section{Western blot}

After treatment, the cells were treated with RIPA lysis buffer for isolation of whole cell protein extract. The nuclear extract was isolated for determining the expression of $\mathrm{NF}-\kappa \mathrm{B}$ and $\mathrm{Nrf2}$. The samples ( $50 \mu \mathrm{g}$ protein) were separated on $10 \%$ SDS-PAGE gels and transferred onto polyvinylidene fluoride (PVDF) membranes. After protein transfer, non-specific sites were blocked with $5 \%$ nonfat dried milk for $1 \mathrm{~h}$ at room temperature. The membrane was washed with TBST and incubated with primary mouse monoclonal antibodies against NF- $\mathrm{BB}, \mathrm{COX}-2, \mathrm{Nrf2}, \mathrm{HO}-1$ and $\mathrm{NQO} 1$ $(1: 1000)$ at $4^{\circ} \mathrm{C}$ overnight. Followed by TBST wash, the membrane was incubated for $1 \mathrm{~h}$ with secondary peroxidase-conjugated goat anti-mouse or -rabbit lgG (1:5000-1:10,000). The bands were visualized with an enhanced chemiluminescence $(E C L)$ system according to the manufacturer's instructions. Densitometric analyses of the western blot bands were performed using Image J software (GE Healthcare Life Sciences).

\section{Statistical analysis}

The data were analyzed using one-way analysis of variance (ANOVA) followed by Tukey's multiple comparison test. All the experiments were performed thrice in triplicate to ensure reproducibility.

\section{Results}

\section{Protective effect of lutein against MIA-induced cytotoxicity}

In order to identify the cytotoxic concentration of MIA, the MTT assay was performed. Monosodium iodoacetate caused dose-dependent cell death compared to control cells. The results show that MIA at a concentration of $4 \mu \mathrm{M}$ for $48 \mathrm{~h}$ showed the $I C_{50}$ value. Further, the cytoprotective effect of lutein was tested at this dose. Lutein was pre-treated for $24 \mathrm{~h}$ at different concentrations followed by MIA treatment. Cells treated with $1 \mu \mathrm{M}$ of lutein showed significant cytoprotection and increased the cell viability to $95 \%$. Cells treated with lutein alone did not show any cytotoxic effect at any of the tested dosages (Figures 1 A, B). Human plasma levels of lutein have been demonstrated to be in the range of $0.25-0.85 \mu \mathrm{M}$ [22]; thus the concentration of $1 \mu \mathrm{M}$ lutein was used for further studies.

\section{Lutein protected against MIA-induced oxidative stress}

The results showed that MIA treatment resulted in a significant increase in oxidative stress status which was reflected in increased ROS and lipid peroxide content compared to control cells. Lutein 
A

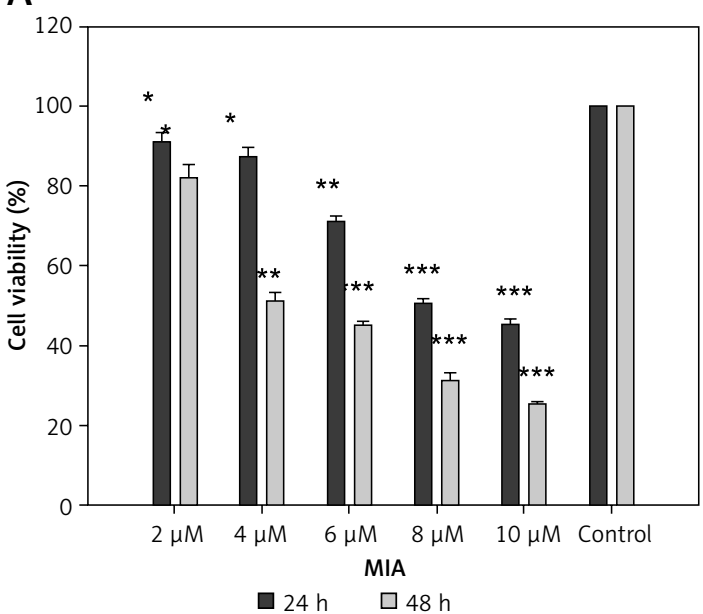

B

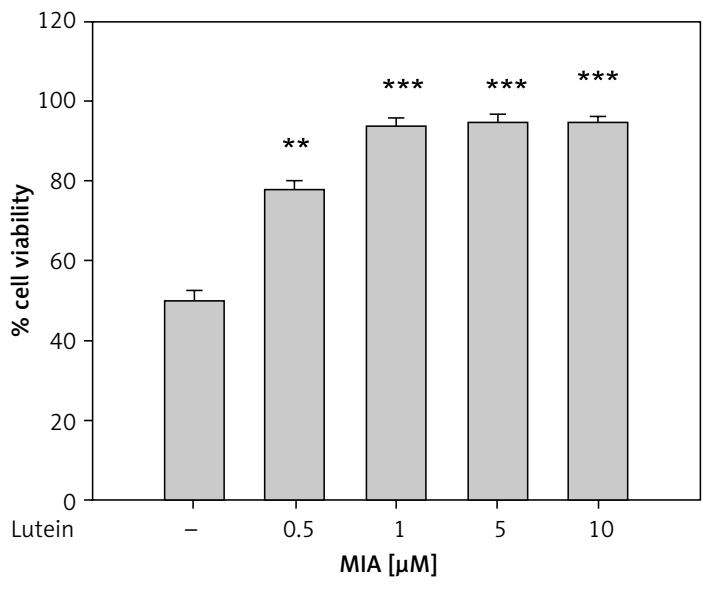

Figure 1. Effect of MIA and lutein against primary chondrocyte cells. Cells were treated with MIA for 24 and $48 \mathrm{~h}$. $\mathrm{IC}_{50}$ concentration was used to determine the protective effect of lutein against MIA-induced cell death. Cell viability was measured using MTT assay. Results were expressed as \% cell viability compared to control. Results are given as the mean \pm SEM. $\mathbf{A}-{ }^{*} p<0.05,{ }^{* *} p<0.01,{ }^{* *} p<0.001$, when compared to control group. $\mathbf{B}-{ }^{* *} p<0.01$, ${ }^{* * *} p<0.001$ when compared to MIA treatment (One-way ANOVA followed by Tukey's multiple comparison). NS - non-significant compared to control group

pre-treatment followed by MIA treatment significantly reduced the ROS and lipid peroxide content compared to MIA-treated cells (Figures $2 \mathrm{~A}, \mathrm{~B}$ ).

\section{Lutein protected MIA-induced toxicity through Nrf2 upregulation}

Nrf2 is a transcription factor involved in regulating redox homeostasis by upregulating antioxidant status. In the present study, we found that MIA treatment showed significant downregulation of Nrf2 and its downstream target antioxidant genes HO-1 and NQO-1. Furthermore, various antioxidant enzymes involved in balancing redox homeostasis such as SOD, CAT, GST and GPX were significantly downregulated compared

A

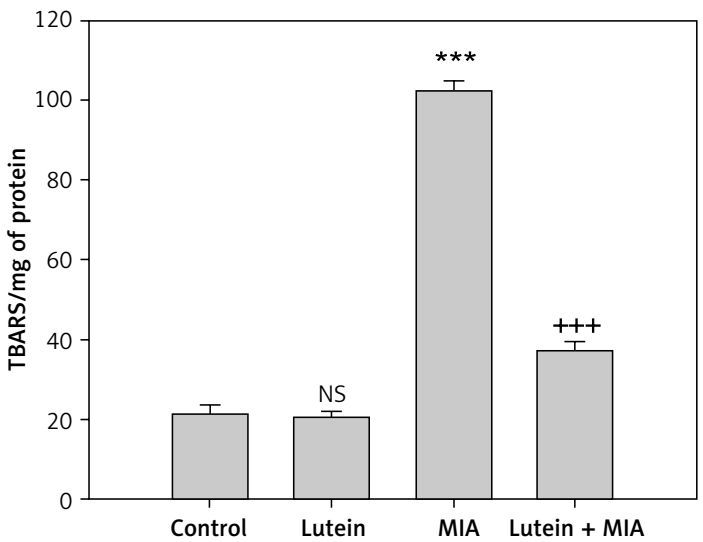

to the control cells. Treatment with lutein showed cytoprotection by significant upregulation of Nrf2, NQO-1 and HO-I. Moreover, there was a concomitant increase in the antioxidant status compared to MIA-treated cells (Figures 3, 4).

\section{Lutein protected against MIA-induced inflammation}

Oxidative stress induces activation of inflammatory responses through NF- $\kappa \mathrm{B}$. In the present study, MIA showed significant upregulation of $\mathrm{NF}-\kappa \mathrm{B}$ and the downstream inflammatory gene COX-2 compared to the control. However, lutein pre-treatment significantly downregulated the protein levels of NF- $\mathrm{KB}$ and COX-2 compared to

B

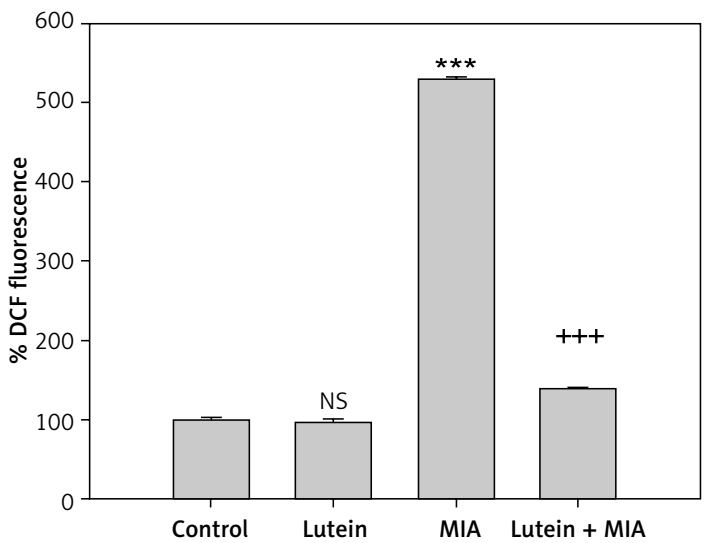

Figure 2. Lutein reduces MIA-induced oxidative stress. A - The results are expressed as nanomoles of TBARS formed/mg of protein. B - The results are expressed as \% DCF fluorescence when compared to control. Results are given as the mean \pm SEM. ${ }^{* * *} p<0.001$, when compared to control group. ${ }^{+++} p<0.001$, when compared to MIA treatment. NS - non-significant compared to control group (One-way ANOVA followed by Tukey's multiple comparison) 
A

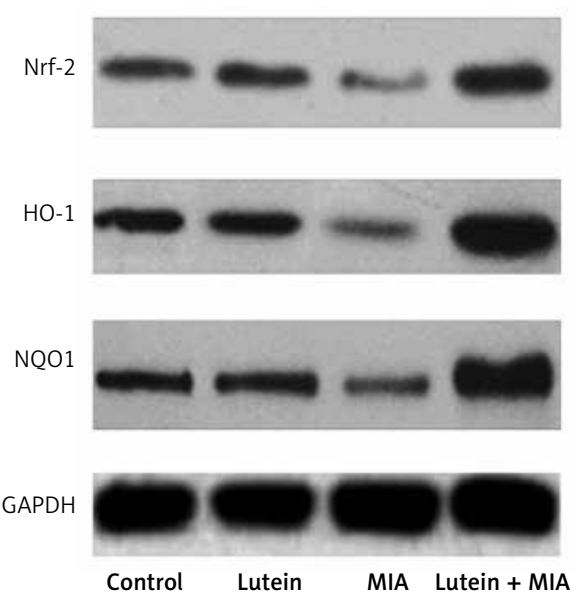

B

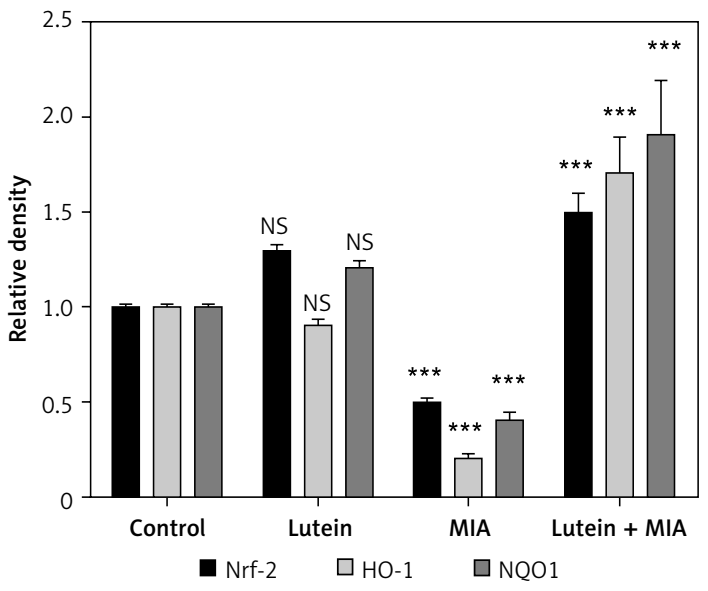

Figure 3. Lutein improves antioxidant mechanism: upregulation of Nrf2, HO-1 and NQO1 expression. Protein expression was analyzed through western blot analysis. Results were expressed as mean \pm SEM. Densitometric analysis show significant downregulation of Nrf2, $\mathrm{HO}-1$ and NQO1 expression in MIA treatment. Lutein treatment upregulated the protein expression compared to MIA treatment. ${ }^{* * *} p<0.001$, when compared to control group. ${ }^{++} p<0.001$, when compared to MIA treatment. NS - non-significant compared to control group

MIA-treated cells and exerted an anti-inflammatory effect (Figure $5 \mathrm{~A}$ ). In order to determine role of lutein and MIA on inflammatory cytokines, the levels of IL-6, IL-1 $\beta$ and TNF- $\alpha$ were determined. Cells treated with MIA showed significant upregulation of inflammatory cytokines compared to the control cells. However, treatment with lutein reduced the levels of cytokines compared to those of MIA-treated cells (Figure 5 B).

\section{Lutein prevented MIA-induced apoptosis}

The results showed that MIA treatment resulted in a significant loss of mitochondrial membrane potential with upregulation of caspase-3 activation compared to that of control cells. Treatment with lutein showed significant restoration of membrane potential with downregulation of caspase- 3 activation compared to that of MIA-treated cells (Figures $6 \mathrm{~A}, \mathrm{~B}$ ).

\section{Discussion}

Osteoarthritis involves abnormal function of chondrocytes with deregulation in matrix proteins and cartilage structure. Until now, reports suggest that apoptosis and initial activation of oxidative stress are important contributors. In the present study, we aimed to identify the potential role of lutein in prevention of MIA-induced osteoarthritis through studying ROS generation, the Nrf2 pathway of antioxidant mechanisms, inflammation and apoptosis.

A cellular toxicity study revealed that MIA caused significant dose-dependent cell death when compared to the control group. The MIA is an established model for osteoarthritis and it results in substantial cartilage degradation through chon-

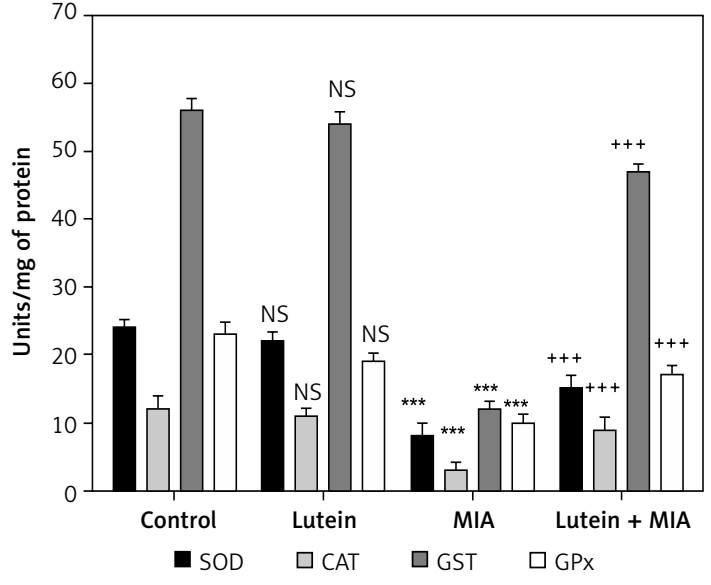

Figure 4. Lutein enhances antioxidant enzyme activities. Results are given as the mean \pm SEM. SOD, CAT, GST and GPx expressed in units/mg protein. ${ }^{* \star} p<0.001$ when compared to control group. ${ }^{++} p<0.001$ when compared to MIA treatment. NS non-significant compared to control group (One-way ANOVA followed by Tukey's multiple comparison)

drocyte apoptosis in vivo and in vitro $[23,24]$. In the present study, MIA treatment resulted in significant upregulation of cellular oxidant status through ROS levels, lipid peroxide content and a concomitant decrease in antioxidant status. Free radical mediated chondrocyte cell death and calcification have been reported to involve ROS, $\mathrm{H}_{2} \mathrm{O}_{2}$ and nitric oxide [14, 25-27]. Since Nrf2 is a prime regulator of redox status, its role in osteoarthritis is not well explored. In the present study, lutein treatment of chondrocyte cells showed significant protection against MIA-induced oxidative stress events which could be attributed to its potential to activate Nrf2. Nrf2, nuclear factor erythroid 2-re- 
A
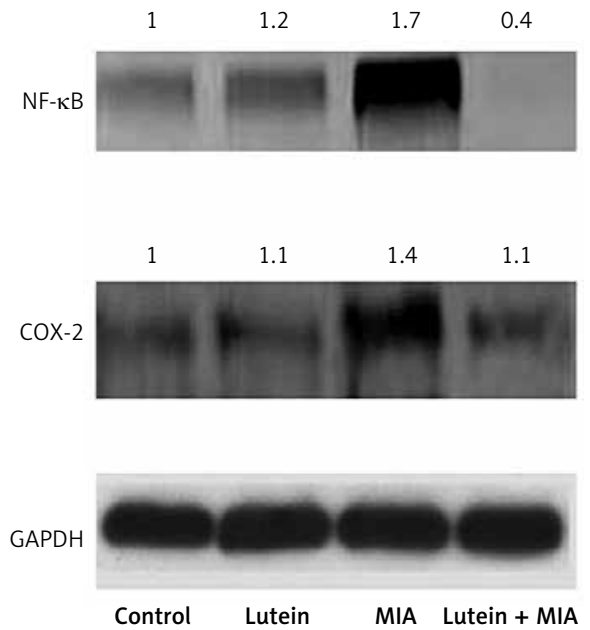

B

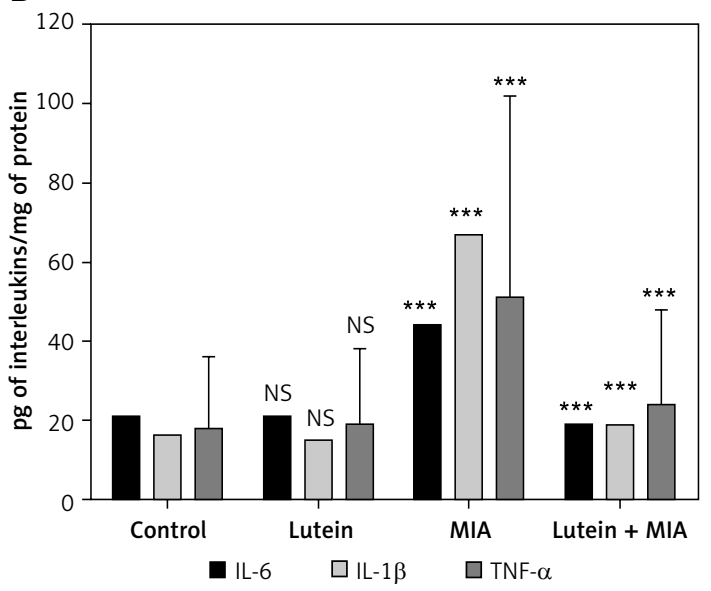

Figure 5 Lutein shows anti-inflammatory effect: downregulation of NF- $\kappa$ B and COX-2 and inflammatory cytokines. A - Protein expression of NF- $\mathrm{\kappa B}$ and COX-2 was analyzed through western blot analysis. Results were expressed as mean \pm SEM. Densitometric analysis shows significant upregulation of NF- $\kappa b$ and COX-2 expression in MIA treatment group. Lutein pre-treatment downregulated the inflammatory proteins compared to MIA treatment. B - MIA treatment showed significant upregulation of IL-6, IL-1 $\beta$ and TNF- $\alpha$ in the MIA treatment group. Lutein pre-treatment downregulated the inflammatory cytokines compared to MIA treatment. ${ }^{\star * *} p<0.001$ when compared to control group. ${ }^{+++} p<0.001$ when compared to MIA treatment. NS - non-significant compared to control group

lated factor 2, is an important transcription factor which regulates the redox imbalance through upregulation of ARE-responsive antioxidant enzymes. Under oxidative stress, Nrf2 functions by cytoprotective activity, but under extremes of redox conditions leads to Nrf2 downregulation, favoring changes in normal cellular processes. Along with significant upregulation of $\mathrm{Nrf2}$, lutein treatment showed increased expression of downstream genes HO-1 and NQO-1. Altogether, lutein reduces oxidative stress through upregulation of Nrf2 and the cytoprotective antioxidant system. Increased antioxidant effects have been documented in vitro and in vivo [28], and protection against LPS-induced uveitis was mediated through its antioxidant property [29]. Attenuation

A

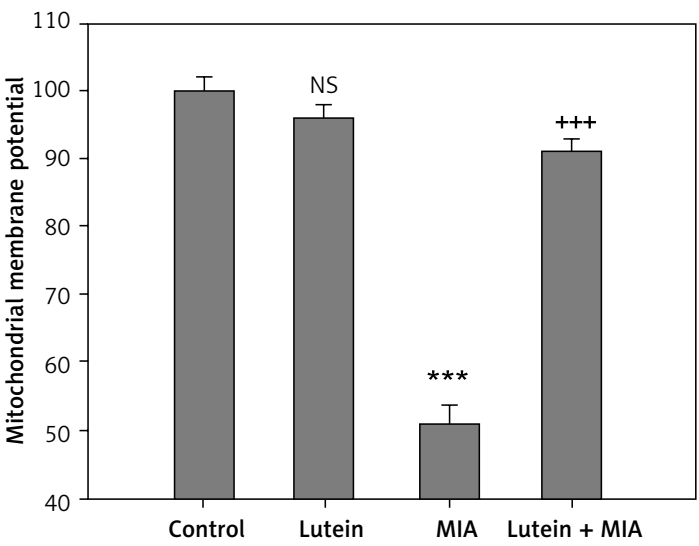

of neuroinflammation in micro-glia cells by lutein was mediated through inhibition of NF- $\mathrm{KB}$ activation and activation of Nrf2 levels [30]. Lutein prevented arsenic-induced reproductive toxicity through enhancing Nrf2 levels and their target proteins HO-1, NQO1 and GST [31].

Inflammation and onset of osteoarthritis are closely linked. In addition, oxidative stress and activation of NF- $\kappa \mathrm{B}$ are well established. Nuclear factor $\kappa B$ is sequestered in the cytoplasm, whereas under oxidative stress it translocates into the nucleus and induces various inflammatory proteins such as COX-2 and iNOS [32].The redox-sensitive transcription factor is activated under enhanced ROS levels, and in the present study there was significant upregulation of NF- $\mathrm{B}$ and COX-2 levels

B

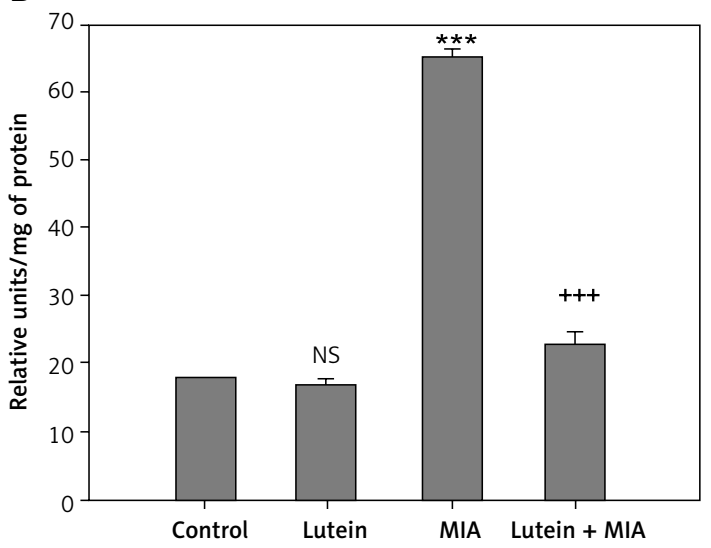

Figure 6. Lutein inhibits apoptosis. Results are given as the mean \pm SEM. Lutein pre-treatment maintained the mitochondrial membrane potential (A) and downregulated caspase-3 activity (B) compared to MIA treatment. ${ }^{* *} P<0.001$ when compared to control group. ${ }^{++} P<0.001$ when compared to MIA treatment. NS - non-significant compared to control group (One-way ANOVA followed by Tukey's multiple comparison) 
during MIA treatment. Inflammatory activation and release of pro-inflammatory cytokines destroy the cartilage matrix; however, ROS levels further enhance the catabolic process with negative regulation in formation of cartilage structure [33, 34]. In order to achieve a balance between these 2 metabolic processes, redox status and inflammation must be effectively downregulated. In the present study, lutein treatment showed significant downregulation in inflammatory proteins (NF- $\mathrm{KB}$ and (OX-2) and release of pro-inflammatory cytokines. Endotoxin-induced uveitis was suppressed by lutein by its anti-inflammatory effects through suppression of activation of NF- $\kappa B, N O, T N F-\alpha$, IL-6, and PGE2 expression [35]. Oxidative stress induced inflammation in gastric epithelial cells was effectively inhibited by reducing ROS levels, inhibition of NF- $\kappa B$ activation and IL-8 expression [36]. Lutein prevented linoleic acid induced inflammatory gene expression and protected retinal pigment epithelial cells through inhibition of NF- $\mathrm{B}$ activation [37].

In conclusion, inflammatory cytokines have a prominent role in chondrocyte mitochondrial dysfunction and cartilage destruction through redox species. Mitochondria regulate apoptosis, whereas loss of membrane potential releases apoptotic factors and induces caspase activation. Caspase- 3 is a key protein involved in apoptosis and executes cell death [38]. In the present study, treatment with lutein significantly regulated MIA-induced loss of membrane potential and caspase- 3 activation and prevented cell death in chondrocytes. Lutein inhibited mammary tumor through inhibition of apoptosis and angiogenesis through increased expression of the pro-apoptotic genes p53 and Bax, and decreased expression of the anti-apoptotic gene $\mathrm{Bcl}-2$ [39]. Lutein along with zeaxanthin and DHA increased photoreceptor survival and differentiation by reducing oxidative stress-induced apoptosis [40]. The present study shows the promising role of lutein in protection against osteoarthritis by modulation of oxidative stress and apoptosis through Nrf2 and NF- $\mathrm{KB}$ expression.

\section{Conflict of interest}

The authors declare no conflict of interest.

\section{References}

1. Busija L, Bridgett L, Williams SR, et al. Osteoarthritis. Best Pract Res Clin Rheumatol 2010; 24: 757-68.

2. Martel-Pelletier J. Pathophysiology of osteoarthritis. Osteoarthr Cartilage 1998; 6: 374-6.

3. Blanco FJ, Lopez-Armada MJ, Maneiro E. Mitochondrial dysfunction in osteoarthritis. Mitochondrion 2004; 4 : 715-28.

4. Huang R, Zhong T, Wu H. Quercetin protects against lipopolysaccharide-induced acute lung injury in rats through suppression of inflammation and oxidative stress. Arch Med Sci 2015; 11: 427-32.

5. Kertmen H, Gürer B, Yilmaz ER, et al. Antioxidant and antiapoptotic effects of darbepoetin-alpha against traumatic brain injury in rats. Arch Med Sci 2015; 11: 1119-28.

6. Mangels AR, Holden JM, Beecher GR, Forman MR, Lanza E. Carotenoid content of fruits and vegetables: an evaluation of analytic data. J Am Diet Assoc 1993; 93: 284-96.

7. Sommerburg O, Keunen JE, Bird AC, van Kuijk FJ. Fruits and vegetables that are sources for lutein and zeaxanthin: the macular pigment in human eyes. Br J Ophthalmol 1998; 82: 907-10.

8. Kim JE, Leite JO, DeOgburn R, Smyth JA, Clark RM, Fernandez ML. A lutein-enriched diet prevents cholesterol accumulation and decreases oxidized LDL and inflammatory cytokines in the aorta of guinea pigs. J Nutr 2011; 141: 1458-63.

9. Kim JH, Na HJ, Kim CK, et al. The non-provitamin A carotenoid lutein inhibits NF-kappaB-dependent gene expression through redox-based regulation of the phosphatidylinositol 3-kinase/PTEN/Akt and NF-kappaB-inducing kinase pathways: role of $\mathrm{H}(2) \mathrm{O}(2)$ in NF-kappaB activation. Free Radic Biol Med 2008; 45: 885-96.

10. Oh J, Kim JH, Park JG, et al. Radical scavenging activitybased and AP-1-targeted anti-inflammatory effects of lutein in macrophage-like and skin keratinocytic cells. Mediators Inflamm 2013; 2013: 787042.

11. Liu ZG, Qi ZC, Liu WL, Wang WZ. Lutein protects against ischemia/reperfusion injury in rat kidneys. Mol Med Rep 2015; 11: 2179-84.

12. Sato $Y$, Kobayashi $M$, Itagaki $S$, et al. Protective effect of lutein after ischemia-reperfusion in the small intestine. Food Chem 2011; 127: 893-8.

13. Sindhu ER, Firdous AP, Preethi KC, Kuttan R. Carotenoid lutein protects rats from paracetamol- carbon tetrachloride- and ethanol-induced hepatic damage. J Pharm Pharmacol 2010; 62: 1054-60.

14. Jiang L, Li L, Geng C, et al. Monosodium iodoacetate induces apoptosis via the mitochondrial pathway involving ROS production and caspase activation in rat chondrocytes in vitro. J Orthop Res 2013; 31: 364-9.

15. Mosmann T. Rapid colorimetric assay for cellular growth and survival: application to proliferation and cytotoxicity assays. J Immunol Methods 1983; 65: 55-63.

16. Royall JA, Ischiropoulos H. Evaluation of 27-dichlorofluorescein and dihydrorhodamine 123 a fluorescent probes for intracellular $\mathrm{H}_{2} \mathrm{O} 2$ in cultured endothelial cells. Arch Biochem Biophy 1993; 302: 348-55.

17. Ohkawa H, Ohishi N, Yagi K. Assay for lipid peroxides in animal tissues by thiobarbitturic acid reaction. Anal Biochem 1979; 95: 351-8.

18. Sun Y, Oberley LW, Ying L. A simple method for clinical assay of superoxide dismutase. Clin Chem 1988; 34: 497-500.

19. Aebi H. Catalase in vitro. Methods Enzymol 1984; 105: 1-126.

20. Habig WH, Pabst MJ, Jakoby WB. Glutathione S-transferases. The first enzymatic step in mercapturic acid formation. J Biol Chem 1974; 249: 7130-9.

21. Paglia DE, Valentine WN. Studies on the quantitative and qualitative characterisation of erythrocyte glutathione peroxidase. J Lab Clin Med 1967; 70: 158-69.

22. Siems W, Grune T. Clinical use of carotenoids. In: Free radicals and diseases: gene expression, cellular metabolism and pathophysiology. Grune T (ed). NATO Science Series, IOS Press 2005; 181. 
23. Wu WJ, Xu XX, Dai Y, Xia L. Therapeutic effect of the saponin fraction from Clematis chinensis Osbeck roots on osteoarthritis induced by monosodium iodoacetate through protecting articular cartilage. Phytother Res 2010; 24: 538-46.

24. Peters HC, Otto TJ, Enders JT, Jin W, Moed BR, Zhang Z. The protective role of the pericellular matrix in chondrocyte apoptosis. Tissue Eng Part A 2011; 17: 2017-24.

25. Hiran TS, Moulton PJ, Hancock JT. Detection of superoxide and NADPH oxidase in porcine articular chondrocytes. Free Radic Biol Med 1997; 23: 736-43.

26. Horton WE, Feng L, Adans C. Chondrocyte apoptosis in development aging and disease. Matrix Biol 1998; 17 : 107-15.

27. Henrotin Y, Kurz B, Aigner T. Oxygen and reactive oxygen species in cartilage degradation: friends or foes? Osteoarthritis Cartilage 2005; 13: 643-54.

28. Sindhu ER, Preethi KC, Kuttan R. Antioxidant activity of carotenoid lutein in vitro and in vivo. Indian J Exp Biol 2010; 48: 843-8.

29. He RR, Tsoi B, Lan F, Yao N, Yao XS, Kurihara H. Antioxidant properties of lutein contribute to the protection against lipopolysaccharide-induced uveitis in mice. Chin Med 2011; 6: 38.

30. Wu W, Li Y, Wu Y, Zhang Y, Wang Z, Liu X. Lutein suppresses inflammatory responses through Nrf2 activation and NF-kappaB inactivation in lipopolysaccharide-stimulated BV-2 microglia. Mol Nutr Food Res 2015; 59: 1663-73.

31. Li SG, Xu SZ, Niu O et al. Lutein alleviates arsenic-induced reproductive toxicity in male mice via Nrf2 signaling. Hum Exp Toxicol 2015; pii: 0960327115595682.

32. Baeuerle PA, Baltimore D. NF-kappa B: ten years after. Cell 1996; 87: 13-20.

33. Guilak F, Fermor B, Keefe FJ, Kraus VB, Olson SA, Pisetsky DS. The role of biomechanics and inflammation in cartilage injury and repair. Clin Orthop Relat Res 2004; 423: 17-26.

34. Goldring SR, Goldring MB. The role of cytokines in cartilage matrix degeneration in osteoarthritis. Clin Orthop Relat Res 2004; 427 Suppl: S27-36.

35. Jin XH, Ohgami K, Shiratori K, et al. Inhibitory effects of lutein on endotoxin-induced uveitis in Lewis rats. Invest Ophthalmol Vis Sci 2006; 47: 2562-8.

36. Kim Y, Seo JH, Kim H. Beta-carotene and lutein inhibit hydrogen peroxide-induced activation of NF-kappaB and IL-8 expression in gastric epithelial AGS cells. J Nutr Sci Vitaminol (Tokyo) 2011; 57: 216-23.

37. Fang IM, Yang $\mathrm{CH}$, Yang CM, Chen MS. Comparative effects of fatty acids on proinflammatory gene cyclooxygenase 2 and inducible nitric oxide synthase expression in retinal pigment epithelial cells. Mol Nutr Food Res 2009; 53: 739-50.

38. Orth K, O'Rourke K, Salvesen GS, Dixit VM. Molecular ordering of apoptotic mammalian CED-3/ICE-like proteases. J Biol Chem 1996; 271: 20977-80.

39. Chew BP, Brown CM, Park JS, Mixter PF. Dietary lutein inhibits mouse mammary tumor growth by regulating angiogenesis and apoptosis. Anticancer Res 2003; 23: 3333-9.

40. Chucair AJ, Rotstein NP, Sangiovanni JP, During A, Chew EY, Politi LE. Lutein and zeaxanthin protect photoreceptors from apoptosis induced by oxidative stress: relation with docosahexaenoic acid. Invest Ophthalmol Vis Sci 2007; 48: 5168-77. 